\title{
Study and analysis on Six Sigma management in SMEs
}

\author{
Shengnan Dai ${ }^{a}$, Mengmeng Zhang ${ }^{b}$ \\ Tianjin University of Technology, School of Management, Tianjin 300384, China \\ adaisir234@sina.com, b864840856@qq.com
}

Keywords: Small and medium enterprises, Six Sigma, DMAIC.

\begin{abstract}
Six Sigma is one of the most important strategic initiatives at the world's pursuit of excellence in corporate management. According to the current status of domestic and foreign enterprises at implement of Six Sigma, in view of the situation and characteristics of SMEs in China, apply SWOT analysis to illustrate the necessity and feasibility of Six Sigma management in SMEs. At the end, use dynamic evolution to import Six Sigma and build a management system.
\end{abstract}

\section{Introduction}

With the economic growing, Six Sigma management development gradually improved. Through the implementation of Six Sigma management, enterprises can reduce costs and improve economic efficiency. As part of our economy, when SMEs confront the fierce market environment and seek their own development, whether through Six Sigma management activities to improve product quality and competitiveness, SMEs must face and solve. From the status and characteristics of SMEs in China, this paper apply SWOT method to illustrate the feasibility of Six sigma management in SMEs, then use dynamic evolution of the method to introduce Six sigma management, and provide some guidance for SMEs.

\section{Connotation of Six Sigma management}

Six Sigma began in the statistical theory, referring to the standard deviation of the normal distribution, used to indicate the degree of dispersion of the data. But in the field of quality management, Six Sigma represent the level of quality.Aiming at continuous improve the business processes to achieve defect-free process design, definite the core processes, measure, analysis, improve, control ${ }^{[1]}$.

Six Sigma integrates a large number of quality tools. The core idea is using the quantitative methods to analyze the factors that affecting the quality of the process, find the key factor to improve and get higher customers' satisfaction results ${ }^{[2]}$.

\section{The status situation and feasibility analysis of SMEs' Six Sigma management}

\subsection{The status situation of SMEs' Six Sigma management}

SMEs promote economic development as an important force for market prosperity and social stability. Promoting moderate growth in the national economy, the SMEs play an increasingly important role. How to adapt the external environment changes, improve their adaptability and competitiveness, SMEs have to face all the problems:1. quantity and wide distribution — Statistics show that SMEs account for more than $98 \%$ of Chinese enterprises, the new jobs for the Chinese contribution is $85 \%$, output value is $60 \%$, profits is $40 \%$ and SMEs also provide $75 \%$ of urban employment chances ${ }^{[3]}$. SMEs involve all of the competitive industries and fields, widely distributed in the first, second and third sectors of industry.2. Although the number of SMEs is dominated, but SMEs lack sufficient capital accumulation, venture and operating capital. At single enterprise-scale, capital, technology, market share, SMEs also have a greater disparity with large enterprises.3. flexible and tenacious vitality__ Due to the small size, less funds needed, less employees, SMEs is easy to product and manage. 4. less competitive, subject to market and external shocks impact greater than big enterprises. 
Promoting Six Sigma management at large-scale enterprises had been developing for a long time. The 2001 Survey of SMEs Quality Management table shows the current stage of China's SMEs in the quality inspection of $31 \%$; in statistical quality control phase accounted for $20 \%$; in total quality management phase accounted for 35\%; in the quality standard system phase accounted for $5 \%{ }^{[4]}$.

If SMEs want to become bigger and stronger, they should strive to improve product and service quality. In September 2006, Aberdeen Group published "Lean Six Sigma Benchmark Report", he said SMEs can also obtain substantial economic returns through the implementation of Six Sigma management ${ }^{[5]}$. Therefore, SMEs must establish the concept of continuous improvement to enhance their strength.

\subsection{Feasibility analysis in the implementation of Six Sigma management in SMEs}

According to the SMEs' characteristics and the status quality management, use SWOT to analysis the implementation of Six Sigma management.

S- Strengths analysis. The successful implementation of Six Sigma management experience tells us that the leader in enterprise plays a key role in the decision. In the SMEs, due to the simple organizational structure, relatively fast communication, once the company decided to implement Six Sigma management, leader can mobilize all resources within the enterprise quickly. But SMEs are often taken to be meticulous and fine strategy. Due to the limitations of their own conditions, the core business of SMEs is often relatively simple. So it is easy to seize its core business and get more profit.

W- Weaknesses analysis. Lacking adequate funds has been one of the main problems of SMEs. Few assets, high risky financing and operating costs, for all the above reasons lead to SMEs lack the necessary financing channels. Through Six Sigma implementation process we use a number of statistical knowledge, so the stuff's professional skills and knowledge requirements are relatively high. Due to the lack of systematic talent introduction and training programs, administrators are more likely to join a good platform for the development of large companies.

O- Opportunities Analysis. With the development of technology, the widespread use of the Internet, business model is undergoing tremendous changes. The e-commerce help SMEs not only reduce the cost but also better improve the quality of services and bring more benefits. SMEs should make good use of the platform, so that products and services will have more chances to sell throughout the country and international markets.

T- Threats Analysis. Our governments always focus on the large enterprises, large enterprises mostly are state-owned enterprises, but SMEs are often non-state-owned. They do not form a complete system of social services network that limit the development and growth of SMEs. According to the SMEs' characteristics in the implementation of Six Sigma management, this paper can draw four kinds of strategic measures: SO strategy (growth-oriented); WO Strategy (twisted type); ST strategy (offensive); WT strategy (defensive).

\section{Build a Six Sigma management system for SMEs}

For SMEs, the quality management system is a gradual process of evolution, the benefits of this dynamic evolution of the system are: the establishment is under limited resources, optimize the allocation of resources; can be adjusted dynamically especially in case of changes in the market. If meet large fluctuations or deviations enterprises can adjust and avoid greater losses ${ }^{[6]}$. Evolution is shown as Figure 1:

If SMEs want to build the implementation of Six Sigma quality management system, enterprise management level should reach the stage of total quality management. Enterprises with total quality management system can successful implement the SPC and SPD. By collecting large amounts of data and using a variety of statistical tools to analyze the cause of the defects and then propose measures for improvement ${ }^{[7]}$.

According to the business objectives, refine the quality objectives to employees of each job duties and work. Pursuing production scene management as core to build enterprises quality assurance, control management, quality cost and measuring instruments system. The framework for the Six Sigma management system is shown as Figure 2. 


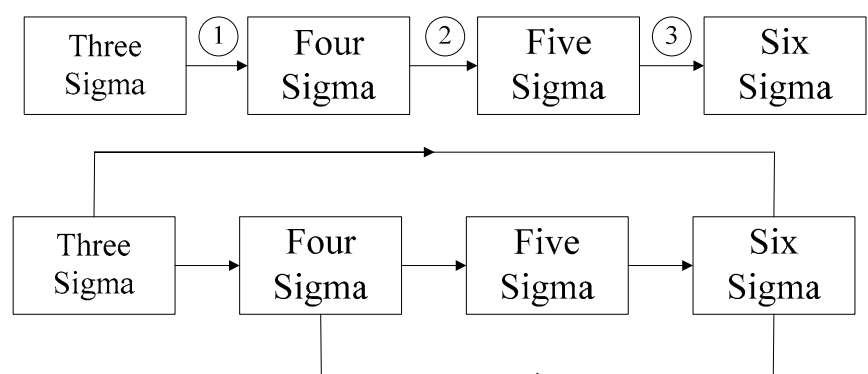

Fig. 1 gradual evolution and leapfrog evolution

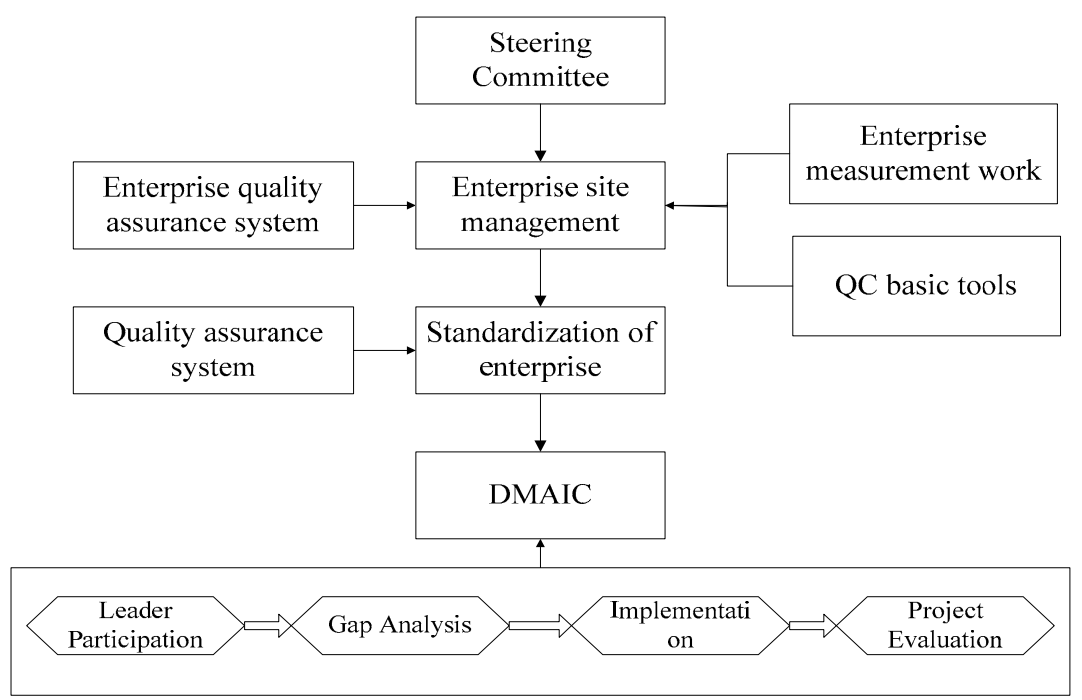

Fig. 2 Six Sigma management system for SMEs

By using the method of value chain to analysis the internal activities of SMEs, combine with total quality management of daily work, choose core business processes, focus on quality improvement of utilization of limited resources to improve the quality management level and market competitiveness.

\section{Issues about the application of Six Sigma management}

Through a number of researches, the paper considers that SMEs need to focus attention to the issues as follows ${ }^{[8-10]}: 1$.Understanding and recognition. For the recognition of Six Sigma strategy is the key to successful implementation. It contains implementing the purpose, meaning of understanding and recognition, and the principles of Six Sigma statistical tools, understanding and recognition.2. Leader's ability and responsibility. Six Sigma management requires from top to bottom stuff, so the strong support from the top leader is the primary condition to ensure the success of Six Sigma projects. It should be firmly grasped to be able to apply.3. Reform the corporate culture. The Six Sigma as a breakthrough strategy, employees need to change attitudes and behavior. It requires companies to strengthen reform management through the motivation and education, encourage employees to accept Six Sigmamanagement.4. Emphasis on training. SMEs should change the traditional concept of quality and increase the awareness of Six Sigma management. Enterprises should implement Six Sigma as an opportunity to build a learning organization as the goal and carry out all-round, multi-level Six Sigma training is an important guarantee for the successful implementation of Six Sigma management.

\section{References}

[1] Y.Q. Hu and Z. He: Science of Science and Management of S.\&.T, Vol. 25 (2004) No.10,p.137.

[2] Z. He, Y.J. Han and M. Zhang: Science of Science and Management of S.\&.T, Vol. 29 (2008), No.2,p.82.

[3]L.Li, Journal of Yuncheng University, (2005) No.12,p.71. 
[4] Y.Wang, China Quality, (2001) No.5,p.11.

[5]Williams,K.IsSix Sigma beneficialfor midsize companies?[N]Strategic Finance,2006-11-23.

[6] C. Gao and H.X. Wen: Pioneering with Science \& Technology Monthly, (2005) No.4,p.59.

[7] Y.J. Yang: China Quality, (2003) No.2,p.20

[8] Z. He, G. Yue and L.L. Wang: Application of Statistics and Management, Vol. 26 (2007) No.9, p1049.

[9] G. H. Fang, H. X. Fang and J. J. Yue: Science of Science and Management of S.\&.T, (2010) No. 1, p.128.

[10] Y. Q. Chen: Commercial Research, Vol. 43 (2010),p.57. 